\title{
0 olhar distanciado: Lévi-Strauss e a história
}

\section{A distant glance: Lévi-Strauss and history}

François Hartog

"A história leva a tudo, mas na condição de distanciar-se dela"! Não estaria aí uma fórmula (uma dentre outras) bem sacrílega para os ouvidos historiadores? No entanto, a todos aqueles que, mais de uma vez, o censuraram por desconhecer, esquecer ou recusar a história, Claude Lévi-Strauss sempre respondeu que lhe atribuía muita importância. "Nada me interessa mais do que a história. E há muito, muito tempo!”, lembra, uma vez mais, em De perto e de longe. ${ }^{1}$ Qual razão ter-se-ia para não se reconhecer suas afirmaçôes? Porém, ele também jamais escondeu que sua tarefa era outra: a elaboração de uma antropologia estrutural, essa "grande tentativa intelectual” que, já em 1959, Merleau-Ponty havia reconhecido e saudado.

O que ele entende, então, por história? Ela é, primeiramente, a "contingência irredutível": a expressão da "potência e da inanidade do acontecimento", diante do que a análise estrutural começa a "inclinar-se", concedendo-lhe "um lugar de destaque". ${ }^{2}$ Aquilo que advém, o imprevisível, e que não é o arbitrário. Contudo,

foi preciso esperar os antropólogos para descobrir que os fenômenos sociais obedeciam a arranjos estruturais. (...) As estruturas apenas se mostram a uma observação praticada de fora. Essa, ao contrário, não pode nunca apreender os processos, que não são objetos analíticos, mas a forma peculiar em que uma temporalidade é vivida por um sujeito. (...) O historiador trabalha a partir de documentos produzidos por testemunhas, elas próprias membros do grupo estudado; enquanto que o etnólogo é sua única testemunha, e uma testemunha, por hipótese, estranha ao grupo. Portanto, para um, a mudança, para outro, as estruturas. ${ }^{3}$ 
Eis o que é claro e nítido. A história é também aquela que LéviStrauss nomeia, em várias ocasiōes, "a história dos historiadores": a disciplina e sua prática. A fórmula, precisa sem dúvida alguma, evoca, apesar de tudo, um pouco o tarefeiro aplicado! O que seria a etnologia dos etnólogos? Nessas condiçôes, pode haver lugar para uma "história estrutural", entendida no sentido estrito ou, menos ainda, para uma "antropologia histórica”? E, contudo, quantas páginas não foram escritas com base nessas duas insígnias? E, contudo, sob a pena do etnólogo, "a idéia de uma história estrutural nada tem que possa chocar os historiadores". ${ }^{4}$

Aquele que tomar um pouco de distância, lançando um olhar retrospectivo, perceberá imediatamente que a obra de Lévi-Strauss demarca meio século do debate entre a antropologia e a história. Mais precisamente, a discussão estabelece-se a partir e em torno de suas reflexões. Debate não significa que foram organizadas grandes justas ou grandes missas, a exemplo daquelas que ocorreram, duas ou três vezes, entre a sociologia e a história no início do século XX. ${ }^{5}$ Antes, prosseguindo seu caminho, ele formulou questôes que os historiadores não se colocavam ou colocavam de outro modo. Se sua prática do olhar distanciado, tendo por objeto a história dos historiadores, às vezes chocou, suscitou mal-entendidos e resistências, ela também os convidou a um deslocamento de seu ponto de vista sobre seu próprio objeto. Ou ainda, a deixar o horizonte único de Hegel e de Marx, de um tempo ritmado pelo progresso e pelo acontecimento, interrogando-se sobre aquilo que eu denomino o regime moderno de historicidade. ${ }^{6}$ Todavia, os debates e os combates focalizaram-se, principalmente, sobre a noção de estrutura, sustentada pela autoridade da lingüística. Ela se dissemina com o sucesso que se conhece, isto é, com seu lote de aproximaçôes e de qüiproquós. Como entendê-la, e quem fixa seu bom uso? Georges Dumézil não se viu convidado para o banquete estruturalista e não foi apresentado como um estruturalista conseqüente??

Para se interrogar sobre a história, não somente aquela dos historiadores e não unicamente aquela dos últimos cinqüenta anos, poderia ser um bom método, não apenas abrir espaço para as questóes, objeções, críticas enunciadas por autores externos à disciplina ou ao domínio, mas partir delas. Em uma palavra, os outsiders contam, às vezes, mais que os insiders, e, em todo caso, há outsiders que pesaram mais que gerações de insiders, sem querer retirar o mérito desses. Nesta corte, que, na tradição 
ocidental, poderia começar com o nome de Aristóteles (e o capítulo 9 da Poética), o nome de Lévi-Strauss teria seu lugar. Se não há nenhuma razão para se pensar que essa sugestão seja válida somente para a história, ela se aplica, eu creio, particularmente bem a ela.

Várias datas (esse "código do historiador", para retomar as próprias palavras de Lévi-Strauss ${ }^{8}$ ), não somente pontuam o debate, mas lhe conferem forma e, para nós, hoje, sentido. Surgem coincidências e estabelecem-se correlações que podem ser apreendidas, sem que, para tanto, seja necessário superinterpretá-las. Um primeiro período iria de 1949 a 1960. No mesmo ano, 1949, aparecem, com efeito, As estruturas elementares do parentesco e $O$ Mediterrâneo e o mundo mediterrânico na época de Filipe II, de Fernand Braudel. A coincidência é fortuita, pois cada um dos livros tem sua própria história, no entanto, a guerra pesou sobre seus destinos: um foi escrito em Nova York, o outro, em um Oflag.* A expressão "história estrutural" aparece, mesmo sob a pena de Braudel, para designar, na conclusão, sua abordagem do Mediterrâneo. Porém, ela não será encontrada, salvo erro, na segunda edição, onde a formulação torna-se apenas "estrutura, história lenta em primeiro lugar"!?

Esse mesmo ano, 1949, é aquele de uma coincidência mais precisa ou mais efetiva. A Revue de métaphysique et de morale consagra um número (julho-outubro de 1949) aos "Problemas da história". Entre os colaboradores: Lévi-Strauss, com um artigo intitulado "História e etnologia", e Lucien Febvre, com "Rumo a uma outra história". ${ }^{10} \mathrm{O}$ historiador o data do Rio de Janeiro: coquetismo! Seria apenas isso? Reunidos, provavelmente ignorando-se mutuamente, os dois artigos não parecem quase coincidir, ainda que, ao final, Lévi-Strauss dê como exemplo de um grande livro de história, "impregnado de etnologia”, o Rabelais de Febvre. Estamos, em todo caso, infinitamente longe de um livro, publicado igualmente em 1949, O mito do eterno retorno, de Mircea Éliade, onde se exprime e se repete um pensamento, desta vez, de recusa da história.

O etnólogo parte, com efeito, dos debates do início do século entre Simiand e Hauser, para valorizar o contraste entre uma história que se ateve ao "programa modesto e lúcido" que lhe fora proposto e a sociologia que, certamente, se desenvolveu muito, mas que não encontrou sua base. ${ }^{11} \mathrm{O}$ outro, o historiador, começa por uma apresentação da Apologia da história, o último e inacabado livro de Marc Bloch, antes de ir, justa- 
mente, na direção de Braudel. A diferença, no início, é, portanto, evidente: eles não falam da mesma história. Lucien Febvre, sabendo que escreve para filósofos, toma cuidado de se apresentar como um "prático" da história. Esse adeus a Marc Bloch é também uma saudação endereçada a Braudel, e o artigo vale como transmissão do bastão. Mas ele faz mais, esboçando a passos largos uma reflexão sobre a situação presente da história.

Para Febvre, há, com efeito, espaço para "acrescentar alguma coisa àquilo que diz Bloch", na medida em que "a partir de 1945, cada ano que vivemos vale por dez". Como de hábito, ele pensa e tece de forma ampla, em escala mundial (visto do Rio de Janeiro). Primeiro chamamento: diferentemente de outras civilizações, a indiana por exemplo, "nossa civilização" é uma "civilização de historiadores" (o credo cristão é um testemunho forte). Esse alargamento do ponto de vista o conduz a notar, de modo breve, que sobre "a historicidade das diversas civilizações, nós sabemos bem pouca coisa”. ${ }^{12}$ Lévi-Strauss, então, prestou atenção nessa nota? Prosseguindo, sempre com a mesma vivacidade de escrita, Febvre exorta os historiadores a abandonarem a religião do documento unicamente escrito. "A história pode se fazer, deve se fazer sem documentos escritos caso eles não existam". E o historiador deve dedicar-se a "fazer falar as coisas mudas, fazê-las dizer aquilo que elas não dizem delas mesmas”. Também, esse livro recente, que fez do Mediterrâneo seu personagem central, vale como "manifesto": ele é um "signo" e uma "data". Seu autor busca, com efeito, assinalar "as forças permanentes que agem sobre as vontades humanas, que pesam sobre elas sem que se dêem conta". ${ }^{13}$

Interrogando-se, para terminar, sobre o alcance da história, Febvre destaca o esquecimento: "esquecer é uma necessidade para os grupos, para as sociedades que querem viver". Não se deixar aniquilar pela pressão dos mortos e questionar a morte em função da vida vale tanto para as sociedades tradicionais como para as outras. Em um caso, é a tradição que é a responsável; no outro, a história, porém, a "necessidade" é a mesma. E ele lança, novamente de passagem, uma idéia de enquete coletiva, na continuação da nota sobre a historicidade das sociedades, sobre o "enorme problema” da tradição. ${ }^{14}$ Essa definição do papel social da história, que deveria "organizar o passado de modo a impedi-lo de pesar demais sobre as costas dos homens", está na continuidade de seu editorial de 1946 para os 
novos Annales. Febvre o havia intitulado "Face au vent". Enfrentar aquilo que recém-acontecera não era, então, ou não era para ele, em todo caso, possível, e enfrentar o mundo devastado saído da guerra era necessário e urgente.

Agora, o etnólogo. Após ter formulado aquilo que nomeia o "dilema" das ciências etnológicas (pretender reconstituir um passado cuja história não podemos atingir, drama da etnologia; querer fazer a história de um presente sem passado, drama da etnografia), e após ter mostrado os impasses do método funcionalista (que, "afinal de contas", foi formulado pelos historiadores ${ }^{15}$ ), Lévi-Strauss examina a démarche da história e da etnologia. Ele chega à conclusão, que rapidamente torna-se famosa, e, ainda mais rapidamente, disputada, simplificada, que: aquilo que as distingue, não é nem o objeto nem o objetivo, mas "a escolha de perspectivas complementares". A história organiza seus dados em relação às "expressões conscientes", e a etnologia em relação às "condições inconscientes", da vida social. ${ }^{16}$ É, com efeito, a "estrutura inconsciente", "subjacente a cada instituição ou costume", que visa o etnólogo. Estabelecendo um inventário de possibilidades inconscientes, ele fornece "uma arquitetura lógica a desenvolvimentos históricos que podem ser imprevisíveis, sem nunca ser arbitrários". Para condensar seu propósito, Lévi-Strauss retoma a fórmula de Marx: "os homens fazem sua própria história, mas eles não sabem que a fazem". ${ }^{17} \mathrm{O}$ historiador vai "do explícito ao implícito", enquanto que o etnólogo vai "do particular ao universal".

Todavia, Lévi-Strauss acrescenta que, hoje, o historiador socorre-se de todo o aparelho das elaboraçôes inconscientes (é aqui que aparece o exemplo do Rabelais). $\mathrm{O}$ etnólogo não está portanto restrito à história, aquela do programa "modesto e lúcido", pela qual havia começado. Ele alcança a história que se estava fazendo, ou seja, aquela do Rabelais de Febvre. A distância, tão marcada no início, reduziu-se. Ele conclui em uma nota de prospectiva: compreender-se-á melhor a complementaridade das duas abordagens no dia em que o etnólogo e o historiador tratarem "conjuntamente" as sociedades contemporâneas. Este "verdadeiro Jano de duas faces", que formam as duas disciplinas, parece, em suma, dividir a exploração de um mesmo terreno: o inconsciente.

Uma outra referência compartilhada, não sem relação com a precedente, desempenha igualmente um papel: a geologia. Em Tristes trópicos, 
o capítulo "Como se tornar etnógrafo" contém uma verdadeira profissão de fé geológica: a "intensa curiosidade que, desde a infância, havia me levado para a geologia”. Sob a desordem aparente existe uma ordem. Para o geólogo, como para o psicanalista, "a ordem que se introduz em um conjunto, à primeira vista incoerente, não é nem contingente nem arbitrária”. ${ }^{18}$ As camadas das temporalidades braudelianas, com suas estruturas folhadas, são emprestadas igualmente da geologia. Um busca nela recuperar um "sentido-mestre", inicialmente invisível; o outro, uma força modeladora que não cesse de formatar, insensivelmente, a história dos homens.

Fim do primeiro ato, porém, alguns anos mais tarde, com uma reprise, quando cada um dos dois artigos conhece uma segunda vida. Febvre retoma o seu em 1953, como conclusão dos Combates pela história: rumo a uma outra história. Em 1958, Lévi-Strauss faz do seu a introdução da Antropologia estrutural. Destaquemos, além do mais, pois esta coincidência é observada pelo próprio autor, que seu livro aparece no ano do centenário de Durkheim, de quem se declara o discípulo "inconstante" e o homenageia, citando Hesíodo como um homem da raça de ouro. Para Febvre, essas páginas são uma conclusão (mas em forma de abertura), enquanto para Lévi-Strauss elas são, propriamente, uma abertura. Em 1949, esse último era ainda um desconhecido, mas que, nesse entretempo, tornou-se o autor de Tristes trópicos, e foi eleito para o Collège de France. Colocado no início de um livro, que vai ser, ele também, um manifesto e uma data, o propósito adquire, evidentemente, um outro relevo.

De fato, uma resposta surge, no mesmo ano, sob a pena de Braudel (que pegou plenamente o bastão). Neste outro texto-manifesto que, rapidamente, tornou-se seu artigo sobre "a longa duração", Braudel dedica-se a um rápido inventário das proposições de Lévi-Strauss, que aparece como um dos principais interlocutores. A história "inconsciente", sim, mas, "bem entendido, a história das formas inconscientes do social". 19 "Os homens fazem a história, mas ignoram que a fazem”. Correto, desde que se entenda por isso que ela faz também os homens e modela seu destino (o ponto de vista do geólogo). Distante do acontecimento, a história inconsciente é, "por excelência, aquela do tempo estrutural". Os modelos, no entanto, 
são apenas hipóteses, sistemas de explicações. Além do mais, o modelo é como um "navio", que sobe ou desce as águas do tempo. $\mathrm{O}$ momento mais significativo é sempre aquele do "naufrágio". ${ }^{20}$ Dito de outra forma, não há modelo que valha fora da duração. Ora, Lévi-Strauss coloca-se sempre, observa Braudel, sobre a rota única da longuíssima duração. Com o parentesco, ele põe em causa um fenômeno "de extrema lentidão, como que intemporal". Trata-se de uma anotação, entre outras tantas, que sublinham um afastamento.

$\mathrm{Na}$ conclusão da segunda edição de O Mediterrâneo, em 1966, Braudel colocará os pingos nos "is" (após o lançamento de $O$ pensamento selvagem em 1962). "Eu sou estruturalista de temperamento", proclama Braudel, acrescentando, em seguida, "pouco solicitado pelo acontecimento e parcialmente solicitado pela conjuntura", ainda que "o estruturalismo de um historiador não tenha relação com a problemática que atormenta, sob o mesmo nome, as outras ciências do homem. Ele não se dirige à abstração matemática das relações que se expressam em funções”. O historiador trabalha "ao nível do solo". Fim do flerte da estrutura e da longa duração ou da imprecisão, às vezes, cômoda, entre uma e outra.

Se Febvre clamava por uma abertura para o mundo, e datava simbolicamente seu artigo do Rio de Janeiro, o autor de Tristes trópicos, que aparece em 1955, voltava de mais longe ainda: dos altos planaltos brasileiros e do mundo dos selvagens. Restabelecendo relações com Montaigne, Léry, Rousseau, Rousseau sobretudo, Lévi-Strauss vê na antropologia, esta empresa, "que renova e expia a Renascença, para estender o humanismo à medida da humanidade". ${ }^{21}$ No momento mesmo em que a França afunda nos anos da descolonização, ele clama a favor de um descentramento e de uma conversão do olhar em direção ao selvagem, que não se encontra, para tanto, promovido à categoria de novo proletário, ou detentor de uma verdade, até então escondida, sobre a condição humana. Daí, então, a reprovação que lhe foi endereçada pelos marxistas de "desesperançar Billancourt"!

Algumas linhas do livro, em uma clara alusão ao Renan da Prière sur l'Acropole, exprimem admiravelmente o descentramento e a ampliação do ponto de vista. "O tombadilho de um barco a caminho da América oferece ao homem moderno, melhor do que Atenas, uma acrópole para a sua ora- 
ção. Nós te recusaremos doravante, deusa anêmica, mentora de uma civilização emparedada! (...) Huronianos, iroqueses, caraíbas, tupi, eis me aquil" 22 Essa antioração, formulada bem no meio do Atlântico, é um adeus ao Mundo Antigo e ao seu humanismo confinado. Se essa postura traduz um novo questionamento da história, desta vez, aquela da filosofia da história do século XIX, aquela de seus estudos de filosofia, ela o conduz também a esboçar os delineamentos daquilo que poderia ser uma outra história universal que (bem entendido, ele não emprega tal expressão), sem esquecer Marx, cederia todo seu lugar a Rousseau, atenta ao homem natural e cuidadosa com os começos.

Vários textos, escritos nesses mesmos anos, vão nessa direção. Tratase de "recusar" não a história (que, na realidade, "consiste inteiramente no seu método"), mas a equivalência entre a noção de história e aquela de humanidade, que nos pretendem impor com o objetivo inconfesso de fazer da historicidade o último refúgio de um humanismo transcendental. ${ }^{23}$ Não mais em Raça e história do que nos Tristes trópicos, a intenção não é de "destruir" a idéia de progresso, mas de "passá-la da posição de categoria universal do desenvolvimento humano para a de modo particular de existência, própria da nossa sociedade (e, talvez, de algumas outras)" ${ }^{24}$

Em Raça e história, encomendado e editado pela UNESCO em 1952, Lévi-Strauss constata que nós estamos, doravante, em uma civilização mundial. ${ }^{25}$ Para fazer justiça à diversidade das culturas, é necessário começar por reconhecer que todas as sociedades estão na história, mas também que o tempo não é o mesmo para todos, de onde surge, primeiramente, a crítica ao "falso evolucionismo", denunciado como a atitude que consiste, para o viajante ocidental, em acreditar que "encontrou", por exemplo, a idade da pedra entre os indígenas da Austrália ou da Nova Guiné. Em seguida, a colocação em perspectiva do progresso. As formas de civilização que éramos levados a imaginar "como escalonadas no tempo" devem antes ser vistas como "estendidas no espaço". A humanidade "em progresso" não é como "um personagem que sobe uma escada, acrescentando a cada um dos seus movimentos um novo degrau a todos aqueles já anteriormente conquistados; evoca antes o jogador cuja sorte está distribuída em vários dados (...). É somente de tempos em tempos que a história é cumulativa, isto é, que as somas se adicionam para formar uma combinação 
favorável" ${ }^{26}$ Além do mais, não existe sociedade cumulativa "em si e por si”: uma cultura isolada não poderia ser cumulativa. As formas de história mais cumulativas foram, com efeito, atingidas por sociedades "que combinaram seus jogos respectivos”, voluntária ou involuntariamente.

Para terminar, a tese central do livro: o mais importante é o afastamento diferencial entre as culturas. É aqui que reside sua "verdadeira contribuição" cultural a uma história milenar, e não na "lista de suas invençôes particulares”. ${ }^{27}$ Também, agora que se entrou em uma civilização mundial, a diversidade deveria ser preservada, mas na condição de entendêla menos como conteúdo do que como forma: conta, sobretudo, o próprio "fato" da diversidade, e menos "o conteúdo histórico que cada época lhe deu". ${ }^{28}$

1960: outra data, outra coincidência, porém provocada. Em 5 de janeiro, Lévi-Strauss pronuncia sua aula inaugural no Collège de France, intitulada "o campo da antropologia". Nela se encontra aquilo que ele nomeia "uma profissão de fé historiadora". Republicada em 1973, ela servirá de introdução à Antropologia estrutural dois. Assim, entre 1949 e 1973, em duas seqüências, 1949-1960, primeiramente, e 1958-1973 (para as reedições), ou seja, aproximadamente um quarto de século, dois textos definem e delimitam o projeto lévi-straussiano. Ora, em ambas a história é mais do que simplesmente presente e mais do que uma beneficiária.

Como reagiram os historiadores aos propósitos de um outsider que parecia saber melhor aquilo que eles mesmos faziam ou poderiam fazer? Em 1958, Braudel, como acabamos de ver, registrou, interpretou as proposiçōes e demarcou, finalmente, os limites de sua aquiescência: sua estrutura não é a minha, que é essa "realidade que o tempo utiliza mal e veicula muito longamente". Desta vez, o cenário será outro. Os Annales publicam um excerto da aula inaugural, sob o título "L'anthropologie sociale devant l'histoire" ${ }^{29}$ A maneira pela qual a escolha foi feita não é desprovida de interesse. Inicia-se, com efeito, com Mauss, que soube proteger a sociologia durkheimiana do perigo da "desencarnação", e finaliza-se com o "sonho secreto" da antropologia social: "se ela se resigna a fazer seu purgatório junto às ciências sociais, é porque espera acordar entre as ciências naturais na hora do juízo final". ${ }^{30} \mathrm{O}$ que pode concluir um leitor dos Annales, senão que após 
Mauss apareceu um novo Durkheim e que a antropologia estrutural aspira alcançar as ciências naturais? Ele não encontrará, particularmente, a passagem, entretanto fundamental, sobre as sociedades frias e as sociedades quentes.

Essa impressão se confirma caso se perceba que o terreno havia sido, de certo modo, preparado pela reedição, em um número anterior $(1,1960)$ do artigo de François Simiand "Método histórico e ciência social”. Publicado originalmente em 1903, e retomado tal qual, ele é colocado na rubrica "Debates e combates" (como aquele de Braudel de 1958). Por que reeditá-lo, por que naquele momento? "O artigo clássico de F. Simiand, explica uma curta nota da redação, é bem conhecido daqueles que fizeram seus estudos antes de 1939. Nós o publicamos, sobretudo, para os jovens historiadores, de modo a permitir-lhes mensurar o caminho percorrido em meio século, e para melhor compreenderem este diálogo da História com as Ciências Sociais, que permanece o objetivo e a razão de ser de nossa Revista" ${ }^{31}$ Mas, ainda? Talvez possa ser isto: as críticas que Simiand dirigia aos historiadores, em 1903, tornaram-se, em uma larga medida, o programa dos Annales (é o caminho percorrido). O diálogo em seguida: o projeto de ciência social (no singular) em torno de uma sociologia regente fracassou e, acrescenta o historiador, convencido da especificidade de seu objeto (o homem em sociedade), somente podia fracassar. O método não é tudo e a história não é apenas um método. Aos historiadores tentados a acreditar que os debates em curso sobre estruturalismo e história são inteiramente novos, convém lembrar que houve, meio século antes, os ataques da sociologia contra a história metódica. Se o estruturalismo pode ser compreendido, no que se refere a sua ambição intelectual, como um novo durkheimismo, localizamo-nos melhor e sabemos o que resta para fazer.

Agora, uma espécie de intermédio. Com O pensamento selvagem, publicado em 1962, Lévi-Strauss persiste e certifica. Os Annales organizam um debate. Prova, portanto, de interesse. Mais exatamente, é Roland Barthes quem reúne um abundante dossiê, sob o título Les sciences humaines et l'auvre de Lévi-Strauss, convidando vários colaboradores, dentre os quais não se conta, a despeito do que fora anunciado, nenhum historiador e apenas um único antropólogo (Edmund Leach) ${ }^{32}$ De qual recepção trata-se então? De uma recepção de fachada? É, provavelmente, em $O$ pensamento selvagem (no capítulo "História e dialética"), que são encontradas as mais rudes formulações para os ouvidos historiadores, como, por exemplo: “o 
etnólogo respeita a história, porém sem atribuir-lhe um valor privilegiado". Convém "recusar a equivalência entre a noção de história e a de humanidade que nos pretendem impor com o objetivo de fazer da historicidade o último refúgio de um humanismo transcendental". "É preciso muito egocentrismo e ingenuidade para crer que o homem está inteiramente refugiado em um só dos modos históricos ou geográficos de seu ser" ${ }^{33}$

O segundo ato: 1971. A iniciativa pertence, desta vez, aos historiadores, ainda que se continue na resposta à "provocação" da etnologia. A operação toma a forma de um número especial dos Annales, intitulado Histoire et structure que começa assim: "a guerra entre a história e o estruturalismo não ocorrerá”. ${ }^{44}$ Senão por outra coisa, poder-se-ia acrescentar, porque ela já havia ocorrido! Surge, então, uma defesa e ilustração da história dos Annales, estruturalista avant la lettre. A divisão consciente/inconsciente não se mantém mais: a história não cessou, depois de meio século, de transpor a fronteira dos dados conscientes. Se é verdade que a experiência particular da Europa não pode pretender medir a história do mundo, não é menos verdadeiro que, na história da própria Europa, há ciclos, crises, momentos de equilíbrio, em suma, alternâncias de quente e de frio. Aqui também, a história não é continuamente ou unicamente cumulativa.

Com esse "balanço", prontamente realizado, atinge-se aquilo que é o objeto mesmo do número: a história cultural. É aqui, estima André Burguière, que a démarche estrutural pode ter "a máxima eficácia”. Como? Por se precaver, de fato, contra o anacronismo, ela é quem melhor pode "dar às formas culturais sua dimensão histórica, isto é, sua distância em relação ao nosso próprio universo mental" . ${ }^{35}$ Por sua própria contribuição, que abre o dossiê, Le temps du mythe, Lévi-Strauss parece engajado nessa nova história cultural estrutural! Pode-se, então, chegar à conclusão, inspirada em Jaurès: "um pouco de estruturalismo distancia da história, muito, reconduz a ela”! ${ }^{36}$

O último ato é representado em uma cena. Lévi-Strauss é convidado por François Furet a pronunciar, em 1983, a 5ª Conferência Marc Bloch. Sob o título "História e etnologia", ela será o último texto publicado por Lévi-Strauss nos Annales. Há vinte anos. De "Etnologia e história”, em 1949, à "História e etnologia”, em 1983! Se é inútil deter-se na permuta dos dois termos, pode-se, no entanto, assinalar a constância da preocupa- 
ção. Todavia, surpresa: ele não está ou não está mais onde se espera. Certamente, a antropologia histórica é nomeada, e se reconhece o interesse em se fazer essa etnologia do passado de nossas sociedades. Duplo interesse: para os historiadores, evidentemente, também para os etnólogos, que dispóem assim de um maior número de experiências sociais, porém, o essencial do propósito está em outro lugar.

Retornando sua divisão entre sociedades frias e quentes, cujo alcance heurístico ele lembra uma vez mais, Lévi-Strauss concentra sua atenção nos "limiares": como uma sociedade se abre para a história? É nesse ponto que o recurso simultâneo à etnologia e à história deveria poder ser mais frutuoso. Conduzindo-nos do Japão medieval à França de Luís XIV, a demonstração busca apreender os momentos onde os "velhos laços de sangue" alteram-se e identifica um tipo de estrutura que é aquele das sociedades "de linhagem". Com as estratégias matrimoniais, encontramo-nos em um terreno onde escolhas individuais e exigências coletivas se interpenetram, onde o dualismo do acontecimento e da estrutura deveria ser, portanto, ultrapassado. Contudo, para conduzir essas pesquisas é necessário recorrer menos à história "nova" que à história "mais tradicionalista e que, às vezes, diz-se, prescrita: soterrada nas crônicas dinásticas, nos tratados genealógicos, nas memórias e em outros escritos consagrados aos assuntos das grandes famílias" ${ }^{37}$ É, portanto, da "pequena história" que o etnólogo tem necessidade! Com a micro-história, os historiadores procuraram responder, a sua maneira, às questôes levantadas sobre a articulação entre escolhas individuais e formas sociais. ${ }^{38}$

Estabelecer o quadro de meio século de divergências tem sua utilidade, mas ela é modesta. Apontar os conflitos de fronteiras, decifrar estratégias, trata-se do ordinário de uma história das disciplinas. Da sociologia à antropologia, de Durkheim, também um outsider, a Lévi-Strauss, novo Durkheim, nós abarcamos um século da história da disciplina histórica e, mais amplamente, das ciências sociais. Apontar os qüiproquós, assinalar a parte dos mal-entendidos e das incompreensões, e, sobretudo, seus efeitos, os working misunderstandings, é uma maneira, rápida, contudo, intelectualmente estimulante, de proceder! Quando as mesmas palavras são mobilizadas, mas entendidas diferentemente, quando são retomadas as mesmas metáforas, mas remetem a significações e a práticas diferentes. 
Os escritos sobre a história de Lévi-Strauss foram e são uma provocação à reflexão para os historiadores (e, evidentemente, para os antropólogos, sobre os quais eu não falo aqui ${ }^{39}$ ). Ocorreu que (irredutível contingência?) ele propôs os termos do debate e delimitou, por um tempo, o espaço da reflexão. Mesmo ignorá-lo (ostensivamente) seria uma maneira de reconhecêlo! Sua estrutura, está claro há muito tempo, não é aquela dos historiadores. Dessa noção, eles fizeram um uso flexível, frágil, aproximativo, desastrado, eventualmente polêmico, quase sempre metafórico, mas também arguto, curioso, freqüentemente inventivo. Ela foi um recurso para considerar as fontes, inéditas ou renovadas, de outro modo, em outro lugar, com outras questôes.

Não há necessidade, convenhamos, de se absorver em um longo inventário para mostrá-lo. Se a antropologia histórica (a história tornandose antropologia, enquanto que o adjetivo histórico viria contestar o estrutural da antropologia de mesmo nome) tivesse sido apenas uma tentativa de defesa diante da ameaça da antropologia estrutural, talvez até uma máquina para se opor a ela, não haveria espaço para se falar longamente da mesma. Porém, todos sabem que ela foi outra coisa. Sob esta bandeira foi escrito toda uma série de livros inovadores, onde essa referência era tudo, salvo unívoca.

Os debates sobre a estrutura, sobre os quais, durante muito tempo, toda a atenção foi focalizada, voltaram. Nada está resolvido, mas, como notava Péguy, "e de repente vira-se às costas" e aparecem outras questôes. Em compensação, nessa démarche classificada, entretanto, de anti-historista, destaca-se, hoje, mais claramente, o lugar dado ao tempo, embora há quinze anos, o tempo seja um problema para nossas sociedades, e que nossas relações com ele tenham perdido sua evidência. Nessa grande "tentativa intelectual”, eu percebi, entendi cada vez mais nitidamente, a exemplo do retorno de uma frase musical, essa atenção dada ao tempo, isto é, aos diversos modos de temporalidades, àquilo que eu terminei por nomear regimes de historicidade.

\section{Notas}

${ }^{1}$ LÉVI-STRAUSS, Claude/ÉRIBON, Didier. De près et de loin. Paris, Odile Jacob, 1988, p. 168, assim como o conjunto do capítulo intitulado "Dans la poubelle de l'histoire" 
(“Na lixeira da história”), pp. 168-176. (Edição brasileira: LÉVI-STRAUSS, C./ÉRIBON, D. De perto e de longe. Rio de Janeiro, Nova Fronteira, 1990, pp. 155-162). (A frase de abertura citada por François Hartog encontra-se em LÉVI-STRAUSS, Claude. La pensée sauvage. Paris, Plon, 1962, p. 348; edição brasileira: O pensamento selvagem. Campinas: Papirus, 1989, p. 291 - NT).

${ }^{2}$ LÉVI-STRAUSS, Claude. Mythologiques. Du miel aux cendres. Paris, Plon, 1990, p. 408.

${ }^{3}$ LÉVI-STRAUSS, Claude. "Les limites e la notion de structure en ethnologie", in BASTIDE, R. (ed.), Sens et usage du terme structure dans les sciences humaines et sociales. Paris, Mouton, 1972, pp. 44-45. (Edição brasileira: BASTIDE, R. (coord.) Usos e sentidos do termo "estrutura". São Paulo, Edusp, 1971, pp. 38-39.)

${ }^{4}$ Os fatos provêm de um tempo mecânico e reversível para a história dos historiadores, aqueles provêm de um tempo estático e irreversível para a história estrutural. LÉVISTRAUSS, Claude. Anthropologie structurale deux. Paris, Plon, 1958, p. 26. (LÉVISTRAUSS, C. Antropologia estrutural dois. Rio de Janeiro, Tempo Brasileiro, 1976, pp. 23-24)

${ }^{5}$ REVEL, Jacques. "Histoire et sciences sociales: lectures d'un débat français autour de 1900", in BÖDEKER, H.E./REILL, P.H./SCHLUMBOHM, J. (eds.) Wissenschaft als kutlerelle praxis, 1750-1900, Göttingen, Vandenhoecck \& Ruprecht, 1999, pp. 377399.

${ }^{6}$ HARTOG, François. Régimes d'historicité. Présentisme et expériences du temps. Paris, Le Seuil, 2003, em particular, as páginas 24-25, 33-36, consagradas a Lévi-Strauss.

7 SMITH, Pierre/SPERBER, Dan. "Mythologiques de Georges Dumézil", Annales, 3-4, 1971, pp. 580-586.

8 "O código só pode, então, constituir-se de classes de datas, em que cada data significa, quando mantém, com outras datas, relações complexas de correlação e oposição.”, LÉVISTRAUSS, Claude. La pensée sauvage. Paris, Plon, 1962, pp. 343-344 (edição brasileira: O pensamento selvagem, Campinas, Papirus, 1989, pp. 287-288). Sobre a data de 1958, ver as variações do próprio Lévi-Strauss, no começo de sua aula inaugural.

* Oflag, nome dado, na Alemanha, durante a Segunda Guerra Mundial, aos campos de prisioneiros destinados aos oficiais (NT).

${ }^{9}$ BRAUDEL, Ferdinand. La Méditerranée et le monde méditerranéen à l'époque de Philippe II. Paris, Armand Colin, 1949, p. 1094.

${ }^{10}$ Os outros autores do número eram: H.I. Marrou, D. Parodi, P. Ricoeur, Tran Duc Tao, G. Darvy e R. Aron.

${ }^{11}$ Trata-se das críticas endereçadas por Simiand a Hauser (e a Seignobos), a propósito de sua rejeição do método comparativo. (Ver SIMIAND, François "Méthode historique et science social”, Revue du synthèse historique, 1903, pp. 1-22 e 129-157); edição brasileira: Método histórico e ciência social. Bauru, Edusc, 2003 - NT)

${ }^{12}$ Eu cito o texto tal como reproduzido em: FEBVRE, Lucien. Combats pour l'histoire. Paris, Armand Colin, 1953, n. 1, p. 420. 
${ }^{13}$ Ibid, p. 432.

${ }^{14}$ Ibid, pp. 436-437.

${ }^{15}$ LÉVI-STRAUSS, Claude. "Ethnologie et histoire”, reproduzido em Anthropologie structurale. Paris, Plon, 1958, p. 22 (edição brasileira: Antropologia estrutural. Rio de Janeiro, Tempo Brasileiro, 1967, p. 31).

${ }^{16}$ Ibid, pp. 24-25 (ed. bras., pp. 33-34).

${ }^{17}$ De fato, a frase de Marx diz: "mas em condiçôes diretamente dadas e herdadas do passado".

${ }^{18}$ LÉVI-STRAUSS, Claude. Tristes tropiques, Paris, Plon, 1955, p. 60 (edição portuguesa: Tristes trópicos. Lisboa, Ed. 70, 1986, pp. 50-51).

${ }^{19}$ BRAUDEL, Ferdinand. Écrits sur l'histoire. Paris, Flammarion, 1969, p. 62 (edição brasileira: Escritos sobre a história. São Paulo, Perspectiva, 1978, p. 60).

${ }^{20}$ Ibid, p. 72 (ed. bras., p. 68).

${ }^{21}$ LÉVI-STRAUSS, Claude. Anthropologie structurale deux, op. cit., p. 44. (ed. bras., p. 39)

* “Désespérer Billancourt": referência à frase de Jean-Paul Sartre a respeito dos trabalhadores da fábrica da Renault em Boulogne-Billancourt, cidade da periferia parisiense que votava regularmente na esquerda . (NT)

${ }^{22}$ LÉVI-STRAUSS, Claude. Tristes tropiques, op. cit., pp. 82-83. RENAN, Ernest. Euvres completes. Paris, Calmann-Lévy, 1948, II, pp. 755-759 (ed. bras. 71-72).

${ }^{23}$ LÉVI-STRAUSS, Claude. La pensée sauvage, op. cit., p. 347 (ed. bras. p. 290).

${ }^{24}$ LÉVI-STRAUSS, Claude. Anthropologie structurale, op. cit., p. 368 (ed. bras. p. 376). 25 "Race et histoire", UNESCO, 1952, reproduzido em: LÉVI-STRAUSS, Claude. Anthropologie structurale deux, op. cit., pp. 377-431 (edição brasileira: 328-366).

${ }^{26}$ LÉVI-STRfAUSS, Claude. Anthropologie structurale deux, op. cit., p. 394 (ed. bras., p. 361).

${ }^{27}$ Ibid, p. 417 (ed. bras., p. 362).

${ }^{28}$ Ibid, p. 421 (ed. bras., p. 366).

${ }_{29}$ Annales, 6, 1960, pp. 625-637. Texto integral em LÉVI-STRAUSS, Claude. Anthropologie structurale deux, op. cit., pp. 11-44 (ed. bras., p. 11-40).

${ }^{30}$ Ibid, p. 29 (ed. bras., p. 26)

${ }^{31}$ Annales, 1, 1960, p. 83. REVEL, Jacques. "Histoire et sciences sociales", op. cit. Revel termina seu texto sobre a reedição de 1960, cujos conflitos ele decifra.

${ }^{32}$ Annales, 19, 1964, 1, 1965.

${ }^{33}$ LÉVI-STRAUSS, Claude. La pensée sauvage, op. cit., pp. 329, 347 (ed. bras. pp. 277, 284, 290).

${ }^{34}$ Annales, 3-4, 1971. Ver também os volumes coletivos Faire de l'histoire, dirigidos por J. Le Goff e P. Nora, Paris, Gallimard, 1974. 
${ }^{35}$ Ibid, p. VI.

${ }^{36} \mathrm{Ibid}, \mathrm{p}$. VII.

37 Annales, 6, 1983, p. 1231. Com o comentário de Lévi-Strauss, De près et de loin, op. cit., pp. 172-173. (ed. bras., p. 157-159).

${ }^{38}$ REVEL, Jacques (ed.). Jeux d'échelle. La micro-analyse à l'expérience. Paris, Seuil/ Gallimard/EHESS, 1996.

${ }^{39}$ ABÉLÈS, Marc. “Avec le temps...”, Claude Lévi-Strauss, Critique, janvier-février, 1999, pp. $42-60$.

\section{Resumo}

O objetivo geral do artigo é o de analisar as relaçôes entre a história e a etnografia, no século XX, a partir da obra do antropólogo Claude Lévi-Strauss. Seus trabalhos, desde As estruturas elementares do parentesco, passando por artigos sobre o tema, pelos Tristes trópicos e pelo Pensamento selvagem, até chegar à conferência Marc Bloch, em 1983, e a De perto e de longe, estimularam o debate entre as disciplinas, caracterizando meio século de discussões e disputas, que promoveram alterações no campo historiográfico. No centro dessa querela intelectual está a noção de "estrutura". De um lado, sempre Lévi-Strauss; de outro, aparecem, sucessivamente, Lucien Febvre, Ferdinand Braudel e o próprio projeto dos Annales.

Palavras-chave: história-etnografia - estrutura - história intelectual

\section{Abstract}

The main purpose of this article is to analyse the relations between history and ethnography in the $20^{\text {th }}$ Century, based on anthropologist Claude Lévi-Strauss' works. His works since The elementary mind, ranging from articles on the theme like Tristes Tropiques and The savage mind, up to Marc Bloch Conference, in 1983, and to Conversations with Claude Lévi-Strauss (De près et de loin), stimulated discussions among disciplines, which characterized half century of debates and controversy causing changes in the historiographic field. In the middle of that intellectual struggle is the notion of "structure". In one side, it's always Lévi-Strauss, in the other, Lucien Febvre, Ferdinand Braudel and the very project of the Annales appear successively.

Key-words: ethnography - structure - intellectual history 